\title{
Insights Into The Importance Of Economic Concepts To Other Introductory Business Courses
}

Penelope J. Prenshaw, (E-mail: prenspj@millsaps.edu), Millsaps College Susan Washburn Taylor, (E-mail: taylosw@millsaps.edu), Millsaps College

\begin{abstract}
The current study uses results of a survey of non-economics business faculty to determine the importance of economic concepts in non-economics introductory business courses. The results give economists data to make the principles of economics course more relevant to the business student and bolster efforts by accrediting bodies to achieve greater business curricular integration.
\end{abstract}

\section{INTRODUCTION}

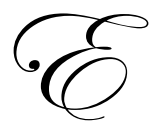

conomics is a building block for additional business knowledge. In most business curricula, the principles of economics sequence is a prerequisite for further business study. Whether we are cognizant of this link in our daily teaching or not, the connection exists and we have little sound evidence about how the economic link is perceived by academic peers in other business disciplines. Economists have their own ideas of which economic concepts are most valued by business peers, but the authors are unaware of any published study which specifically asks business faculty to provide feedback on the importance of economic concepts to courses for which the principles sequence is a pre-requisite. Given that academic disciplines are typically separated on campuses geographically and as a practical matter have little interdisciplinary dialogue, the current study bridges an important gap.

From a teaching perspective, this knowledge may prove useful. According to Siegfreid (2000), only a small fraction of students in introductory economic courses pursue an economics major. If we as teachers can tap into the concepts which link economics to other disciplines, business students may have greater interest in the course and thus leave the course with greater recall.

The belief that economics is a building block for future business knowledge and not merely a separate entity is also supported by the significant changes among business schools regarding the emphasis on integrated course work. These changes began after the AACSB, in 1992, allowed for greater flexibility in curriculum design with new, more relaxed standards. Subsequently, business schools began evaluating their own curriculum based on these new standards [Mayes; Heide; and Smith 1993]. The reviews of the literature, considering both the perspectives of educators and practitioners, highlight the call for greater breadth and integration within the business curriculum, and a stronger connection to reality [Schaupp and Lane 1992; Kenworthy 1996; Toth 1999; Bliss and Potter 2000]. This study provides some commonalities which could be used for this integration.

To address these issues, the current study seeks to determine the importance of economic concepts in noneconomics business courses. Fifteen economic concepts are identified for examination: Operation of Markets, Consumer Behavior, the Economics of Production and Cost, Opportunity Cost, Elasticity, Market Structures, Comparative Advantage, Basic Aggregate Data, Short-term Economic Fluctuations/Business Cycle Theory, Economic Growth, Monetary Policy, Fiscal Policy, Market Imperfections and Regulation, Principles of Macroeconomics, and Principles of Microeconomics. A web based survey seeks to determine how important these concepts are to the introductory undergraduate course in other business disciplines, specifically, accounting, finance, management, marketing, and management information systems. 
Section II of the paper presents our survey methodology. Section III highlights the survey results regarding the importance of the principles of economics sequence while Section IV examines the importance of specific economic concepts. A discussion of the implications of this study as well as ideas for further research are found in Section V.

\section{METHODOLOGY}

An online survey was conducted through a secure web server. The questionnaire was designed to measure the importance of basic economic concepts as they relate to introductory undergraduate business courses. Specifically, subjects were asked to indicate "the importance of (economic concept) to the introductory undergraduate course in your discipline.” Survey responses ranged from 1 (very important) to 5 (not important). The fifteen concepts included in the questionnaire and listed in column 1 of Table 2 generally correspond to the major themes in the typical principles of economics course sequence. Many of these concepts may be further broken down into subcategories, but doing so would lengthen the questionnaire significantly and thus potentially affect response rates. ${ }^{1}$

Subjects were a convenience sample of 146 business faculty contacted in the spring of 2001. The sample was chosen based on e-mail addresses obtained from the discipline-related national organizational membership list (e.g., American Marketing Association membership list). From each discipline’s list, email addresses were generated.

Respondents were nicely dispersed across the business disciplines: 31 accounting; 29 finance; 39 management; 25 marketing; and 20 management information systems (2 missing data points). Eighty-five percent of respondents had taught the undergraduate introductory course in their discipline with in the past five years, indicating a current knowledge of course content.

Due to the web survey employed and its nonprobability design, it is important to note the threat of coverage and sampling error and our inability to present error estimates. Coverage error, or the proportion of the target population that potentially can be reached via the web, is not of great concern due to the high penetration of Internet access among faculty at academic institutions. Sampling error is more of a concern; however, comparing our sample with population data from the National Center for Education Statistics, we find similarity based on institutional classification. In our sample, $16.4 \%$ were classified as a research institution, compared with $7.5 \%$ for the population. At the doctoral classification level, our sample was at $17.8 \%$ compared to $6.8 \%$ for the population. At the comprehensive level, our sample was at $35.6 \%$ compared to $33.2 \%$ for the population. Finally, at the baccalaureate level, our sample was at $26.7 \%$ compared to $52.5 \%$ for the population. In addition, the sample was well dispersed across academic rank with $10.3 \%$ at the instructor level; $30.1 \%$ at the assistant professor level; $27.4 \%$ at the associate professor level; and $30.1 \%$ at the full professor level (3 missing data points).

Finally, with attention directed towards minimizing measurement error, several design features were employed with the web-based questionnaire. We employed radio buttons versus entry boxes, which requires less effort and lowers item nonresponse (Couper, Traugott, and Lamias 2001). Additionally, the color for line items were alternated to facilitate accuracy; however, no other graphic features were included so as to minimize download time and increase response rates.

\section{THE IMPORTANCE OF MACRO-AND MICROECONOMICS PRINCIPLES COURSES}

Survey participants were asked to gauge the overall importance of the Principles of Macroeconomics and Principles of Microeconomics courses to the introductory course in their discipline. Table 1 presents the mean importance rating of each course for all business disciplines and for each specific discipline. Recalling that participants ranked concepts on a scale from 1 (very important) to 5 (not important), the lower the average, the more

\footnotetext{
${ }^{1}$ The authors are aware that there may be semantic differences in the use of terms across disciplines. In order to combat this, the survey included a brief elaboration of each concept to reduce confusion. Appendix I provides a copy of the survey instrument.
} 
important the concept. Generally speaking, averages less than or equal to 3.0 are indicative of concepts which are important to the discipline.

As can be seen in Table 1, principles of microeconomics is important to all business disciplines surveyed as the overall average value is 2.52. The average value for each discipline is less than 3.0 in all cases. Principles of Microeconomics is most important to Marketing (2.0) and least important to MIS (2.80). Principles of Macroeconomics does not fare as well in importance with an overall average of 3.39. The only discipline which finds the macro principles course valuable to its introductory course is Finance. One plausible explanation for the relative insignificance of macroeconomics is that the economic prosperity of the preceding decade may have caused business faculty to focus on other issues when recession was not at the forefront. There is little need to emphasize delivering bad news in management courses, for example, when there is no need for downsizing. ${ }^{2}$

\section{THE IMPORTANCE OF SPECIFIC ECONOMIC CONCEPTS}

Column 2 of Table 2 displays the mean importance rankings for thirteen specific economic concepts as they relate to the introductory undergraduate courses among all business disciplines surveyed. Highlighting the centrality of basic supply and demand, Operation of Markets was found to be the most important concept among all five disciplines surveyed with a mean rating of 2.39. Other microeconomic topics followed closely in overall importance, specifically Production and Costs, Opportunity Cost, and Consumer Behavior. Given that all disciplines except Finance indicated that Principles of Macroeconomics was unimportant for the introductory course in their discipline, it is not surprising that macroeconomic concepts lie at the bottom of the importance list with fiscal policy having the highest mean rating, 3.80 .

Are the differences in overall importance statistically significant? Table 3 displays paired t- tests to compare the mean of the paired differences between overall average value of each concept [the values presented in Column 2 of Table 2]. Using a 95\% confidence interval of the differences, the p value (Sig. (2-tailed)) associated with each comparison is indicated for 3 levels: $<0.0005,<0.005$, and $<0.05$, indicating that a difference in means departs significantly from 0 at the associated significance levels. In pairwise tests, Operation of Markets does not significantly differ from the average importance rating of other microeconomic topics: Production and Costs, Opportunity Cost, and Consumer Behavior. Furthermore, these same concepts are significantly more important in pairwise tests as compared to all the other economic concepts. Monetary and Fiscal Policy are consistently significantly less important than all other economic concepts.

Table 2 [columns 3-7] also provides a breakdown of the average importance values and their rank within each business discipline. Of those disciplines, the finance professors clearly find all the economic concepts important to their introductory course as only two ratings are higher than 3.0. Interestingly, Marketing also sees economic concepts as important with 10 concepts receiving a rating which is less than 3.0. Management and MIS both indicated five economic concepts with importance ratings less than 3.0: Operations of Markets, Cost and Production, Opportunity Cost, Consumer Behavior, and Comparative Advantage. Accounting professors found only four economic concepts important to their introductory courses, each agreeing that Operation of Markets, Cost and Production, and Opportunity Cost are important.

The disciplinary ratings of concepts are also ranked in Table 2. While the overall average rating of Operation of Markets was highest, it was ranked first by no individual discipline. Accounting and Management both ranked Costs and Production as the most important economic concept for the introductory undergraduate course in their

\footnotetext{
${ }^{2}$ Similar breakdowns by institutional classification, institution size, and academic rank of respondent are reported in Appendix II. These results are consistent with those above in that microeconomics is of greater importance to introductory non-economics business courses than macroeconomics. Upon initial inspection of breakdown by rank, there appears to be a "learning effect" which comes with education or experience as Instructors rate both micro and macroeconomics courses as less important than their counterparts at the Assistant, Associate, and Full Professor level. However, "Instructors" as a group are dominated in their field by management and MIS and have no marketing and little finance representation. We feel this disciplinary distribution accounts for the phenomenon.
} 
discipline while Consumer Behavior ranked highest amongst the Marketing faculty surveyed. Finance and MIS rated Opportunity Cost as most important.

With the exception of Finance, the macroeconomic concepts fall to the bottom of the ranking list with Monetary Policy and Fiscal Policy ranked last. Finance stands out as the sole discipline to rank macroeconomic concepts in the top half of their ranking with Basic Aggregate Data ranked fifth, Monetary Policy fourth, and Business Cycle Theory sixth. The micro-oriented concepts of comparative advantage $\left(12^{\text {th }}\right)$ and elasticity $\left(11^{\text {th }}\right)$, rank at the bottom of the Finance list.

\section{IMPLICATIONS OF THE STUDY}

First, the results are valuable to economists seeking to make the principles of economics course more relevant to the business student. Noting that comparative advantage is important to Management, the economics instructor could incorporate a management application into a lecture on comparative advantage which is often discussed only in terms of international trade. For example, discussions of Home Depot's decision to pursue a low cost strategy versus the neighborhood Ace Hardware choosing to differentiate themselves via consumer service would be instructive.

Similarly, as Finance values macro-related issues more highly than do other disciplines, instructors should make students aware of how the data or theory has relevance to the introductory finance course. Federal Reserve actions influencing interest rates, for example, are discussed extensively in the principles of macroeconomics course. This analysis of Fed action has significant implications for stock market valuations which students at the introductory level may not be aware of.

To drive home the point, if economics instructors teach the material in a vacuum, students will apply it in a limited, pedantic way, not realizing the value of the logic to other issues in which they may have a more direct interest. Broadening the concept to include more extensive business examples reinforces the importance of economic logic.

Second, given the call for cross-functional integration within the business curriculum (Porter 1997), this study identifies commonalities across disciplines which will aid in curriculum design. Undergraduate students often view their course work, especially courses in different disciplines, as discrete units having no connectivity. We as academics often perpetuate this idea in our bid for more majors. The disciplines of business, however, can be more closely linked as evident by this study. Economic concepts provide for this commonality and simple references to other business disciplines and their application of economic ideas, as discussed above, will create a more unified educational experience for students.

Finally, this study demonstrates that all of the business disciplines find Principles of Microeconomics and specifically several basic micro concepts to be important to the introductory course in their area. What is lacking across the disciplines is a reinforcement of the macro concepts, a finding disheartening to macroeconomists everywhere. This result may stem from the ten years of economic prosperity which preceded the survey which was administered in Spring 2001. That prosperity may have lulled respondents into a sense of macroeconomic complacency. Another interpretation is that business faculty may lack appropriate macroeconomic applications. These applications do exist, however. The Conference Board's Consumer Confidence Index (CCI) offers potential for rich applications of a macroeconomic concept for integration across the business disciplines. As a survey of consumer attitudes, the CCI can be studied by marketers interested in exploring the attitudinal theory driving these responses. In prioritizing and designing e-business initiatives, MIS instructors can employ the CCI to better understand consumer spending patterns and consumer expectations about the job market. Industry analysis in management courses would benefit from understanding the confidence readings of the CCI because of its predictability for spending patterns among such industries as housing, automobiles, and travel.

This study is the first of several to examine the interrelationships between business and economics using survey data. Future research will take this assessment tool a step further and will give economists valuable feedback 
on how much economic logic students actually take with them as they progress to the other discipline-specific introductory courses. Thus, while it is important for the economics instructor to understand the importance of economic concepts to the business introductory courses, we also need to understand how well the student processes these concepts and applies them in the business major.

Table 1

Mean Importance of Microeconomic and Macroeconomic Principles Courses

\begin{tabular}{|l|c|c|c|c|c|c|}
\hline Principles Course & Overall & Accounting & Finance & Management & Marketing & MIS \\
\hline Microeconomics & 2.55 & 2.68 & 2.09 & 2.78 & 2.00 & 2.89 \\
\hline Macroeconomics & 3.51 & 3.84 & 2.27 & 3.49 & 3.32 & 4.00 \\
\hline
\end{tabular}

Table 2

Mean Importance Rating (Rank in Parentheses)

(1)

\begin{tabular}{|c|c|c|c|c|c|c|}
\hline (1) & (2) & (3) & (4) & (5) & (6) & (7) \\
\hline Economic Concepts & Overall & Accounting & Finance & Management & Marketing & MIS \\
\hline Operation of Markets & 2.39 & $2.43(2)$ & $1.66(2)$ & $2.69(3)$ & $1.96(3)$ & $2.95(4)$ \\
\hline $\begin{array}{l}\text { Economics Of } \\
\text { Production \& Cost }\end{array}$ & 2.43 & $2.03(1)$ & $2.48(3)$ & $2.53(1)$ & $2.71(7)$ & $2.45(2)$ \\
\hline Opportunity Cost & 2.41 & $2.45(3)$ & $1.62(1)$ & $2.84(5)$ & $2.56(6)$ & $2.40(1)$ \\
\hline Consumer Behavior & 2.62 & $2.81(4)$ & $2.86(8)$ & $2.74(4)$ & $1.60(1)$ & $3.00(5)$ \\
\hline $\begin{array}{l}\text { Comparative } \\
\text { Advantage }\end{array}$ & 2.79 & $3.57(8)$ & $3.07(12)$ & $2.66(2)$ & $1.80(2)$ & $2.65(3)$ \\
\hline Market Structures & 3.08 & $3.37(6)$ & $2.86(8)$ & $3.05(7)$ & $2.48(5)$ & $3.80(11)$ \\
\hline Elasticity & 3.09 & $3.23(5)$ & $3.00(11)$ & $3.42(10)$ & $2.0(4)$ & $3.75(10)$ \\
\hline $\begin{array}{l}\text { Market Imperfections } \\
\text { and Regulation }\end{array}$ & 3.15 & $3.65(9)$ & $2.72(6)$ & $3.03(6)$ & $2.92(8)$ & $3.55(8)$ \\
\hline Economic Growth & 3.20 & $3.70(10)$ & $2.86(.8)$ & $3.13(8)$ & $2.92(8)$ & $3.35(7)$ \\
\hline $\begin{array}{l}\text { Short-Term Econ } \\
\text { Fluctuations/Business } \\
\text { Cycle Theory }\end{array}$ & 3.27 & $3.42(7)$ & $2.72(6)$ & $3.45(11)$ & $3.46(11)$ & $3.30(6)$ \\
\hline Basic Aggregate Data & 3.28 & 4.07 (13) & $2.66(5)$ & $3.18(9)$ & $2.96(10)$ & $3.60(9)$ \\
\hline Monetary Policy & 3.37 & $4.03(12)$ & $2.52(4)$ & $3.79(12)$ & 3.88 (13) & $4.26(13)$ \\
\hline Fiscal Policy & 3.80 & $4.00(11)$ & 3.10 (13) & 3.89 (13) & $3.84(12)$ & $4.25(12)$ \\
\hline
\end{tabular}


Table 3

Paired T Tests $P$ Values

\begin{tabular}{|c|c|c|c|c|c|c|c|c|c|c|c|c|}
\hline & 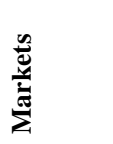 & 悹 & 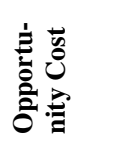 & 㤩总 & 豈蒫 & ن & 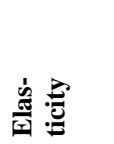 & 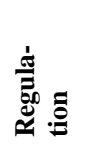 & 总 & 总 总 & 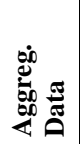 & 竞: \\
\hline Costs/Prod. & .077 & & & & & & & & & & & \\
\hline Opp. Cost & 1.00 & $.007 *$ & & & & & & & & & & \\
\hline $\begin{array}{l}\text { Consumer } \\
\text { Behavior }\end{array}$ & .086 & $.002 * *$ & .056 & & & & & & & & & \\
\hline Comp. Adv. & $.000 * * *$ & $.000^{* * *}$ & $.000 * * *$ & $.001^{* *}$ & & & & & & & & \\
\hline $\begin{array}{l}\text { Market } \\
\text { Structures }\end{array}$ & $.000^{* * *}$ & $.000^{* * *}$ & $.001^{* *}$ & .079 & 312 & & & & & & & \\
\hline Elasticity & $.003 * *$ & $.000 * * *$ & $.006 *$ & .118 & .170 & .185 & & & & & & \\
\hline Regulation & $.000^{* * *}$ & $.000^{* * *}$ & $.000^{* * *}$ & $.004 * *$ & .891 & .354 & $.041^{*}$ & & & & & \\
\hline $\begin{array}{l}\text { Economic } \\
\text { Growth }\end{array}$ & $.000^{* * *}$ & $.000^{* * * *}$ & $.000^{* * * *}$ & $.002^{* *}$ & .795 & .212 & $.037 *$ & .856 & & & & \\
\hline $\begin{array}{l}\text { Business } \\
\text { Cycles }\end{array}$ & $.001^{* *}$ & $.000^{* * * *}$ & $.000^{* * * *}$ & $.038 *$ & .620 & .778 & .405 & .335 & .083 & & & \\
\hline $\begin{array}{l}\text { Aggregate } \\
\text { Data }\end{array}$ & $.000^{* * * *}$ & $.000^{* * * *}$ & $.000^{* * *}$ & $.000^{* * *}$ & $.019 *$ & $.001^{* *}$ & $.001^{* *}$ & $.017^{*}$ & .077 & $.006 *$ & & \\
\hline $\begin{array}{l}\text { Monetary } \\
\text { Policy }\end{array}$ & $.000^{* * *}$ & $.000 * * *$ & $.000 * * *$ & $.000^{* * *}$ & .055 & $.001^{* *}$ & $.000^{* * *}$ & $.043 *$ & $.048 *$ & $.003^{* *}$ & .646 & \\
\hline $\begin{array}{l}\text { Fiscal } \\
\text { Policy }\end{array}$ & $.000^{* * *}$ & $.000^{* * * *}$ & $.000^{* * * *}$ & $.000^{* * * *}$ & .123 & $.006 *$ & $.001^{* *}$ & .070 & .118 & $.004 * *$ & .541 & .573 \\
\hline
\end{tabular}

\section{REFERENCES}

1. Bliss, R.T. and M. E. Potter. 2000. Integrating the Undergraduate Business Curriculum: The Case of Babson College. Journal of Business Education Spring (1), 1-13.

2. Couper, M. P., M. W. Traugott, and M. J. Lamias. 2001. Web Survey Design and Administration. Public Opinion Quarterly 65, 230-253.

3. Kenworthy, A.L. 1996. Linking Business Education, Campus Culture and Community: The Bentley ServiceLearning Project. Journal of Business Ethics 15 (1), 121-131.

4. Mayes, B.T., D. Heide and E. Smith. 1993. Anticipated Changes in the Business School Curriculum: A Survey of Deans in AACSB Accredited and Non-Accredited Schools. Journal of Organizational Change Management 6 (1), 54-63.

5. Porter, L.W. 1997 A Decade of Change in the Business School: From Complacency to Tomorrow. Selections 13 (2), 1-8.

6. Schaupp, D. and M.S. Lane. 1992. Teaching Business Ethics: Bringing Reality to the Classroom. Journal of Business Ethics, 11 (3), 225-229.

7. Siegfried, J. J. 2000. Undergraduate Economics Degree Trends Through the 1990s Journal of Economic Education 31 (3), 296-300.

8. Toth, E.L. 1999. Models for Instruction and Curriculum. Public Relations Review, 25 (1), 45-53. 


\section{APPENDIX I}

\section{Survey Instrument}

Thank you for agreeing to participate in our survey.

When answering the following sets of questions, to the best of your knowledge, please base your responses as they relate to the introductory undergraduate course(s) in your discipline. In so doing,(1) rate the importance of the economic concept to the course(s), and (2) if you respond 1, 2, or 3 in importance, rate the level of student understanding of the economic concept upon entering the course(s).

\section{Operations Of Markets}

Indicate below the importance of the operation of markets (supply, demand, price determination) to the introductory undergraduate course in your discipline by clicking the circle above the appropriate number. If you respond 1, 2, or 3, please indicate the extent of student understanding in the area upon entering the course by clicking the circle above the appropriate number.

\section{Consumer Behavior}

Indicate below the importance of consumer behavior (consumer preferences, budget constraints and decision making) to the introductory undergraduate course in your discipline by clicking the circle above the appropriate number. If you respond 1, 2, or 3, please indicate the extent of student understanding in the area upon entering the course by clicking the circle above the appropriate number.

\section{The Economics Of Production and Cost}

Indicate below the importance of the economics of production and cost to the introductory undergraduate course in your discipline by clicking the circle above the appropriate number. If you respond 1,2 , or 3 , please indicate the extent of student understanding in the area upon entering the course by clicking the circle above the appropriate number.

\section{Opportunity Cost}

Indicate below the importance of opportunity cost to the introductory undergraduate course in your discipline by clicking the circle above the appropriate number. If you respond 1,2 , or 3 , please indicate the extent of student understanding in the area upon entering the course by clicking the circle above the appropriate number.

\section{Elasticity}

Indicate below the importance of elasticity (price, income, and supply elasticity) to the introductory undergraduate course in your discipline by clicking the circle above the appropriate number. If you respond 1, 2, or 3, please indicate the extent of student understanding in the area upon entering the course by clicking the circle above the appropriate number.

\section{Market Structures}

Indicate below the importance of market structures (pure competition, monopoly, etc.) to the introductory undergraduate course in your discipline by clicking the circle above the appropriate number. If you respond 1, 2, or 3, please indicate the extent of student understanding in the area upon entering the course by clicking the circle above the appropriate number. 
Comparative Advantage

Indicate below the importance of comparative advantage to the introductory undergraduate in your discipline course by clicking the circle above the appropriate number. If you respond 1,2 , or 3 , please indicate the extent of student understanding in the area upon entering the course by clicking the circle above the appropriate number.

\section{Basic Aggregate Data}

Indicate below the importance of basic macroeconomic data (GDP, inflation, unemployment, etc.) to the introductory undergraduate course in your discipline by clicking the circle above the appropriate number. If you respond 1, 2, or 3, please indicate the extent of student understanding in the area upon entering the course by clicking the circle above the appropriate number.

\section{Short-Term Economic Fluctuations/Business Cycle Theory}

Indicate below the importance of short-term economic fluctuations/business cycle theory to the introductory undergraduate course in your discipline by clicking the circle above the appropriate number. If you respond 1, 2, or 3, please indicate the extent of student understanding in the area upon entering the course by clicking the circle above the appropriate number.

\section{Economic Growth}

Indicate below the importance of economic growth to the introductory undergraduate course in your discipline by clicking the circle above the appropriate number. If you respond 1,2 , or 3 , please indicate the extent of student understanding in the area upon entering the course by clicking the circle above the appropriate number.

\section{Monetary Policy}

Indicate below the importance of monetary policy in economic stabilization (Federal Reserve actions) to the introductory undergraduate course in your discipline by clicking the circle above the appropriate number. If you respond 1, 2, or 3, please indicate the extent of student understanding in the area upon entering the course by clicking the circle above the appropriate number.

\section{Fiscal Policy}

Indicate below the importance of fiscal policy in economic stabilization (use of federal taxes and government spending to manipulate the economy) to the introductory undergraduate course in your discipline by clicking the circle above the appropriate number. If you respond 1, 2, or 3, please indicate the extent of student understanding in the area upon entering the course by clicking the circle above the appropriate number.

\section{Market Imperfections and Regulation}

Indicate below the importance of market imperfections and government regulation (antitrust, environmental regulation, etc.) to the introductory undergraduate course in your discipline by clicking the circle above the appropriate number. If you respond 1, 2, or 3, please indicate the extent of student understanding in the area upon entering the course by clicking the circle above the appropriate number.

\section{Principles of Macroeconomics}

Indicate below the overall importance of the concepts taught in the Principles of Macroeconomics course (aggregate economy, monetary policy concepts, etc.) to the introductory undergraduate course in your discipline by clicking the circle above the appropriate number. If you respond 1,2 , or 3 , please indicate the extent of student understanding in the area upon entering the course by clicking the circle above the appropriate number. 


\section{Principles of Microeconomics}

Indicate below the importance of concepts taught in the Principles of Microeconomics course (consumer behavior, market structure concepts, etc.) to the introductory undergraduate course in your discipline by clicking the circle above the appropriate number. If you respond 1, 2, or 3, please indicate the extent of student understanding in the area upon entering the course by clicking the circle above the appropriate number.

What introductory economics courses are required for the entry level course in your discipline?

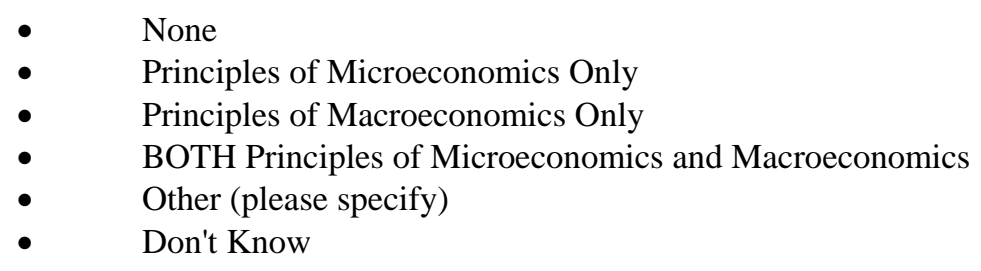

At your institution:

- $\quad$ Is economics located within the College of Business? Yes No

- $\quad$ Is there an economics major? Yes No

- $\quad$ Is there a business administration major? Yes No

What is your primary discipline?

- $\quad$ In the past five years, have you taught the undergraduate introductory course in your discipline? Yes No

What is your rank?

- Instructor Assistant Professor Associate Professor Full Professor

How many years have you taught in higher education?

- $\quad$ Less than 5 years 5 - 9 years 10 - 19 years More than 20 years

What is the size of your institution?

- $\quad$ Less than 25002500 - 50005001 - 10000 Greater than 10000

What classification best describes your institution?

- $\quad$ Research University (awards 50 or more doctoral degrees yearly)

- $\quad$ Doctoral University (awards at least 10 doctoral degrees yearly)

- $\quad$ Comprehensive University or College (awards 20 or more master's degrees yearly)

- $\quad$ Baccalaureate College (primarily undergraduate college which awards $40 \%$ or more of degrees in liberal arts)

- $\quad$ Other (please specify) 
Appendix II

Mean Importance Of Microeconomic And Macroeconomic Principles Courses By Institutional Classification, Institution Size, And Academic Rank

\begin{tabular}{|c|c|c|}
\hline & Macro Principles & Micro Principles \\
\hline Institutional Classification & & 2.92 \\
\hline Research & 3.58 & 1.92 \\
\hline Doctoral & 3.08 & 2.65 \\
\hline Comprehensive & 3.21 & 2.44 \\
\hline Baccalaureate & 3.44 & 2.60 \\
\hline Institution Size & & 2.78 \\
\hline Less than 2500 & 3.25 & 2.45 \\
\hline 2500-5000 & 3.68 & 2.41 \\
\hline 5001-10,000 & 3.55 & 3.39 \\
\hline Greater than 10,000 & 3.21 & 2.61 \\
\hline Academic Rank & & 2.38 \\
\hline Instructor & 3.73 & 2.45 \\
\hline Assistant & 3.58 & \\
\hline Associate & 3.05 & \\
\hline Full & 3.4 & \\
\hline
\end{tabular}

NOTES 